\title{
A Comparison of Macular Structure Imaged by Optical Coherence Tomography in Preterm and Full-Term Children
}

\author{
Monika Ecsedy, ${ }^{1}$ Anna Szamosi, ${ }^{1}$ Cecilia Karkó ${ }^{2}$ Laszlo Zubovics, ${ }^{3}$ Balazs Varsányi, ${ }^{1}$ \\ Janos Németh, ${ }^{1}$ and Zsuzsa Récsán ${ }^{1}$
}

Purpose. Macular anatomic abnormalities were examined by optical coherence tomography (OCT) imaging in premature children and compared with those of full-term children.

Methods. In a prospective case-control study, premature patients 7 to 14 years of age were divided into three groups (group I, laser-treated retinopathy of prematurity [ROP]; group II, spontaneously regressed ROP; group III, no ROP), and age-matched children (group IV). All the eligible 74 eyes had normal-appearing posterior pole, myopia $\leq 3 \mathrm{D}$, and best corrected visual acuity 1.0. When both eyes of a subject were eligible for the study, one eye was randomly selected (10 eyes of 10 children in each group). Retinal thicknesses of the macula measured by OCT3 were compared. The correlation between central foveal thickness and prematurity (gestational age at birth $\leq 30$ weeks; birth weight $\leq 1250$ g) or ROP was determined.

Results. The mean foveal and central retinal thicknesses decreased significantly in group I (laser-treated ROP) and group IV (term birth). Significant differences in central retinal thickness were found between the premature groups and full-term children (Mann-Whitney U test). The cutoff point of central retinal thickness, determined by receiver operating characteristic curve was $209 \mu \mathrm{m}$. The general estimating equation model statistics found a significant effect of ROP severity $(P=0.003)$, $P$ value for the category of prematurity was 0.063 .

Conclusions. The central retinal thickness was significantly higher in the preterm groups than in the full-term group. This subtle macular modification may be related mainly to ROP. Prematurity had only a marginally significant role. (Invest $O p b$ thalmol Vis Sci. 2007;48:5207-5211) DOI:10.1167/iovs.061199

Tnfants born at less than 32 weeks' gestation are at high risk 1 of retinopathy of prematurity (ROP), myopia, amblyopia, strabismus, and optic nerve abnormalities ${ }^{1-3}$ linked to the degree of prematurity ${ }^{4}$ and the presence of cerebral damage. ${ }^{5}$ These children have also been reported to have an increased

From the ${ }^{1}$ Department of Ophthalmology, Semmelweis University, Budapest, Hungary; the ${ }^{2}$ Department of Ophthalmology, St. Borbala County Hospital, Tatabanya, Hungary; and the ${ }^{3}$ Neonatal Care Unit, Schöpf-Merei County Hospital, Budapest, Hungary.

Presented at the World ROP Meeting, Vilnius, Lithuania, September 2006.

Submitted for publication October 6, 2006; revised January 28, May 14, and July 31, 2007; accepted September 5, 2007.

Disclosure: M. Ecsedy, None; A. Szamosi, None; C. Karkó, None; L. Zubovics, None; B. Varsányi, None; J. Németh, None; $Z$. Récsán, None

The publication costs of this article were defrayed in part by page charge payment. This article must therefore be marked "advertise$m e n t "$ in accordance with 18 U.S.C. $\$ 1734$ solely to indicate this fact.

Corresponding author: Zsuzsa Récsán, Department of Ophthalmology, Semmelweis University, Budapest, Mária utca 39. Hungary 1085; recsan@szem2.sote.hu. incidence of long-term color vision ${ }^{6,7}$ and contrast sensitivity impairments ${ }^{3}$ unrelated to major ocular disease or cerebral damage. It is also not uncommon for adolescents with a history of mild ROP to have mild deficits in letter acuity that cannot be corrected by careful refraction, even in the absence of clinical ROP in the macula and the absence of early high refractive errors. ${ }^{8}$ All these observations and several animal studies 9,10 investigating the development of the fovea suggest that ROP and prematurity itself alters the development of the central retina.

Recent studies documented this subtle macular dysfunction by using multifocal electroretinography (mfERG) to investigate ROP-associated alterations in neural retinal development. ${ }^{11}$ However the long-term outcome of central retinal morphologic changes has not yet been studied directly. Optical coherence tomography (OCT) imaging of the macular area is known to be highly reproducible, and it is also a useful tool for the measurement of macular volume and foveal thickness. ${ }^{12,13}$ In this study, we used OCT to examine the macular structure and thickness in formerly preterm children with mild or no sequelae of regressed ROP, compared to age-matched normal control subjects. Macular dimensions were also correlated with prematurity status and ROP.

\section{Methods}

This study was approved by the local human research ethics committee (TUKEB 101/2006; Semmelweis University, Budapest, Hungary) and is in accord with the Declaration of Helsinki. Written informed consent was obtained from all participants' parents or guardians.

\section{Study Design}

The present study was a prospective case-control study that included formerly preterm children 7 to 14 years of age who had received treatment and follow-up at our department. These patients constituted groups I, II, and III of the study. All the selected eyes had a normalappearing posterior pole. The best corrected visual acuity was 1.0. The refractive error ranged from +0.5 to $-3.0 \mathrm{D}$ spherical equivalent. Patients were excluded from the study if they had a history of cerebral damage, residua of ROP (i.e., macular dragging, macular fold, partial retinal detachment involving the macula, or total retinal detachment), nystagmus, amblyopia, and myopia higher than $-3.0 \mathrm{D}$ spherical equivalent. Children 7 to 14 years of age who had been born at full term comprised the control group (group IV). All control subjects were generally healthy, with no ocular disease. When both eyes of a subject were eligible for the study, one eye was randomly selected.

\section{Preterm Subjects}

Patients treated and observed at our department were selected from the records. A letter of invitation for the study was mailed to 90 families, of whom 37 families replied, and 40 children responded. All the patients were enrolled who met the enrollment criteria. The Kruskal-Wallis $\mathrm{H}$ test showed no significant differences between the 
TABLE 1. Mean Data of the Four Groups

\begin{tabular}{|c|c|c|c|c|c|}
\hline & Group I & Group II & Group III & Group IV & $\boldsymbol{P}$ \\
\hline Age (y) & $\begin{array}{c}9.35 \pm 2.3 \\
(7-13)\end{array}$ & $\begin{array}{c}10 \pm 1.7 \\
(7-12)\end{array}$ & $\begin{array}{l}9 \pm 1.3 \\
(7-10)\end{array}$ & $\begin{array}{c}9.36 \pm 1.4 \\
(7-12)\end{array}$ & 0.430 \\
\hline Spherical equivalent (D) & $\begin{array}{c}-0.81 \pm 1.6 \\
(-3.0-1.0)\end{array}$ & $\begin{array}{l}-0.32 \pm 1.4 \\
(-3.13-1.88)\end{array}$ & $\begin{array}{c}0.75 \pm 1.2 \\
(-2.63--0.27)\end{array}$ & $\begin{array}{l}-0.62 \pm 1.3 \\
(-2.63--0.27)\end{array}$ & 0.501 \\
\hline Axial length (mm) & $\begin{array}{l}22.6 \pm 0.8 \\
(21.3-23.6)\end{array}$ & $\begin{array}{l}22.3 \pm 0.8 \\
(20.9-23.5)\end{array}$ & $\begin{array}{l}22.43 \pm 0.47 \\
(21.91-23.22)\end{array}$ & $\begin{array}{l}23.1 \pm 0.4 \\
(22.8-23.5)\end{array}$ & 0.131 \\
\hline
\end{tabular}

Ten eyes of 10 children were assigned to each group. Results of Kruskal-Wallis H test, asymptomatic significance level for the four groups. All groups were compared with each other.

four groups in the following parameters: age, spherical equivalent, and axial length. Data are summarized in Table 1.

Group I: Laser-Treated Patients. Both eyes of the patients underwent argon blue-green or 810-nm diode laser treatment for stage-3 threshold ROP. Laser coagulation was performed by using indirect binocular ophthalmoscopy. Twenty-six eyes of 13 children were examined. After the exclusion criteria were applied, 17 eyes of 10 patients were eligible. The mean \pm SD (range) birth weight was $1134 \pm 368(640-1620) \mathrm{g}$. The mean gestational age at birth was $27.8 \pm 2.6(24-32)$ weeks.

Group II: Patients with Stage 1 or 2 ROP. Higher stages than stage 1 or 2 ROP were not documented in the acute phase within a few months of birth. Fifteen patients responded, 17 eyes of 10 patients matched with the enrollment criteria. Mean birth weight was $1364 \pm 571(850-1500) \mathrm{g}$. Mean gestational age at birth was $29.4 \pm$ $2.8(26-34)$ weeks.

Group III: Patients without ROP. No ROP was documented during the neonatal period. Twenty-four eyes of 12 patients were checked; both eyes of 2 patients were excluded because of myopia (spherical equivalent, $>-3.0 \mathrm{D}$ ). Twenty eyes of 10 patients were included. Mean birth weight was $1527 \pm 467$ (900-2030) g. Mean gestational age at birth was $30.7 \pm 2.5(26-34)$ weeks.

\section{Control Subjects}

The control subjects (Group IV) consisted of an age-matched group of 10 healthy children, who had been born at full term (mean birth weight, $3400 \pm 200.5$ [3100-3900] g) and were recruited by letter from a local primary school. Twenty eyes of 10 children were enrolled.

Ophthalmic assessment included the following steps in order. Refraction and keratometry readings were obtained with a calibrated autokeratorefractometer (model Accuref-K 9001; Shin Nippon, Tokyo, Japan). Best corrected visual acuity was measured at $5 \mathrm{~m}$ with the Snellen chart. An orthoptic examination was performed in each participant. The Lang test was used to screen amblyopia. Slit lamp biomicroscopy and ophthalmoscopy were performed. Digital fundus photographs of the macula and the periphery in nine gaze positions were taken of each eye.

The OCT measurements (StratusOCT3; Carl Zeiss Meditec, Dublin, CA) were performed in a dim room after pupil dilatation with tropicamide $(50 \mathrm{mg} / 10 \mathrm{~mL})$ drops. The pupils were dilated to at least $5 \mathrm{~mm}$ diameter before the measurements. The OCT examination was analyzed (version 4.1 software; Carl Zeiss Meditec). Macular measurements were performed with the Early Treatment of Diabetic Retinopathy Study (ETDRS) macular mapping protocol, which consists of six individual line scans regularly arranged in a radial pattern with a default scan length of $6 \mathrm{~mm}$. Each line scan was composed of 128 individual A-scans, so that a 6-mm diameter macular area was sampled at 768 separate points. An internal-fixation target was used in all scans, with the location of each scan on the retina monitored using an infraredsensitive video camera. Scans were performed using default axial length $(24.46 \mathrm{~mm})$ and refractive error (OD) for consistency with usual clinical practice. The patients were asked to fixate an internal target and the operator centered the macular scans on the foveal pit. The scans were accepted if free of artifacts (boundary errors and decentra- tion), and complete cross-sectional images were seen for all individual line scans. Retinal thickness was automatically determined by the instrument software as the distance between the internal limiting membrane and retinal pigment epithelium. Measurements were provided for three concentric regions. The central disc (foveal region) was a region with a radius of $0.5 \mathrm{~mm}$, and the inner and the outer rings had outer radii of 1.5 and $3 \mathrm{~mm}$, respectively, and were divided into four quadrants. Average retinal thickness was provided for each of the nine regions, and total macular volume (TMV) was calculated by the software automatically from these data. Foveal thickness (FT) was measured by the software at the cutting point of the six individual line scans. The average retinal thicknesses of the four inner and the four outer segments were also calculated.

The axial length of the eye was measured by contact $10-\mathrm{MHz}$ A-mode ultrasound (Ultrascan Imaging System; Alcon Laboratories, Fort Worth, TX). The scan was taken on to the center of the cornea perpendicularly, and the patients were asked to fixate the internal target. The automatic biometry program calculated the mean of eight measurements. The results were considered valid when the SEM was under 0.05 .

\section{Statistical Analysis}

Statistical analysis was performed with commercial software (SPSS ver. 15.0 for Windows; SPSS, Chicago, IL). $P \leq 0.05$ was considered statistically significant, with a $95 \%$ CI. The distribution of the data was checked by Shapiro-Wilks W test, which showed non-normally distributed data. Therefore nonparametric tests were applied. No significant differences were found between the left and right eyes of a patient for spherical equivalent, axial length of the globe, and OCT parameters (Mann-Whitney test). Only one eye of a patient was enrolled in each group. The right and left eyes were randomized on the basis of heads or tails. The Kruskal-Wallis $\mathrm{H}$ test, Mann-Whitney test, and receiver operating characteristic (ROC) curve were performed on 10 eyes of 10 children in each group. The Kruskal-Wallis H test was used to compare the parameters (i.e., age, axial length of the globe, spherical equivalent, and OCT parameters) of the four groups. The null hypothesis was that there are no differences between the groups. If the test showed a significant difference for a parameter, the groups were compared by the Mann-Whitney test. The cutoff point of central foveal thickness was determined (ROC). The central retinal thicknesses were the test variables, prematurity was the static variable, with the category 0 used for full-term subjects (group IV) and 1 for the preterm children (groups I-III). The null hypothesis was that the true area $=0.5$. General estimating equations (GEE) were calculated for all eligible eyes (54 eyes of 30 preterm children and 20 eyes of 10 full-term subjects), to determine whether prematurity or ROP is in the background of the thicker foveal region compared with the control group. The working correlation matrix was independent. A logit link function was applied. The patients' identity number was used to determine the subject. The patients' eyes were compared to determine the within subject effect. The cutoff point of central retinal thickness was the dependent parameter $(1, \leq$ cutoff point, 2 , cutoff point $<$ central retinal thickness measured by OCT). The following factors were analyzed: stages of ROP (1, ROP stages 1 to $3 ; 2$, no ROP), birth weight $\leq 1250 \mathrm{~g}$, and gesta- 

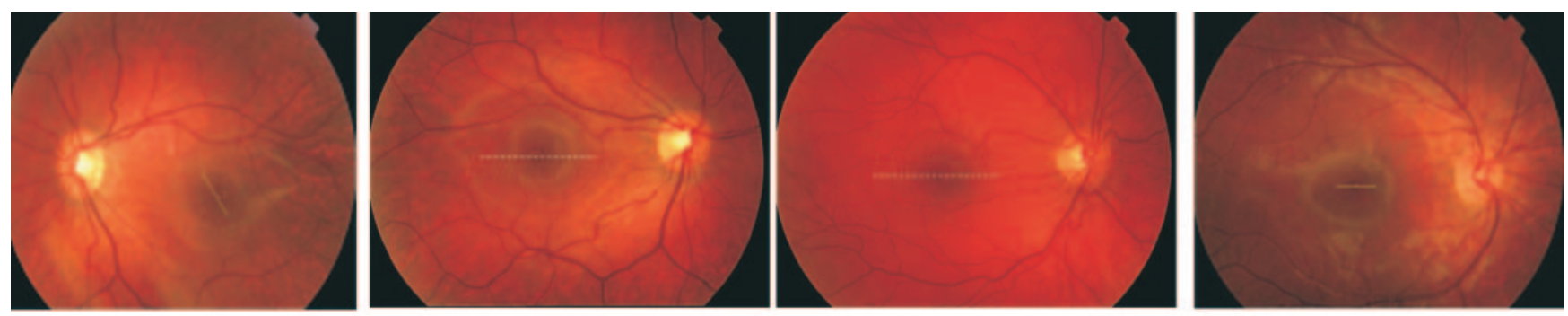

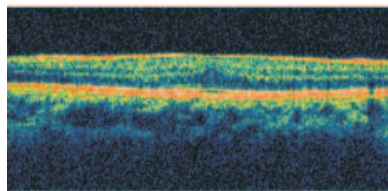

Group I

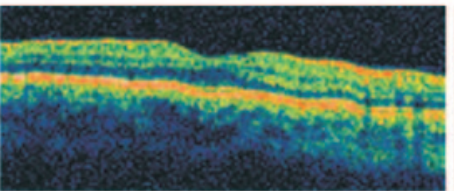

Group II

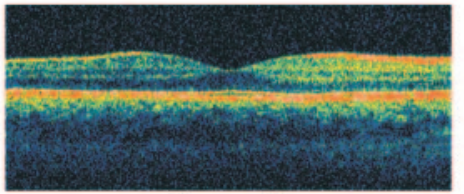

Group III

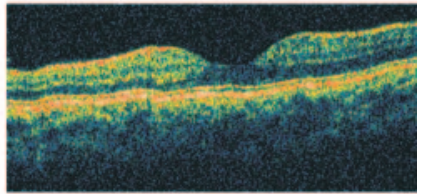

Group IV

FIGURE 1. Digital fundus photographs and OCT scans of representative cases from each of the four groups. Light reflex appeared as a ring around the fovea in groups I and II, whereas it was a spot just in the center of the fovea in groups III and IV. The central retinal thickness was the largest in group I, and the mean values descended in groups II and III toward the values of group IV. The fovea was thickened and the foveal depression was flattened in the groups I, II, and III. The inner retinal layers seem to be continued above the photoreceptor layer. Group I, preterm patients with stage 3 threshold ROP regressed after laser coagulation; group II, preterm patients with stage 1 or 2 ROP regressed spontaneously; group III, preterm patients without ROP; group IV, age matched children born at full term.

tional age at birth $\leq 30$ weeks. These two latter parameters were considered together as well.

\section{Results}

On the macular scans, as well as on the topographic macular thickness maps, a thicker foveal central region can be seen in groups I, II, and III (premature groups), compared with group IV (full-term control). The layer corresponding to the inner retina seems to continue even under the foveal depression (Fig. 1). All these findings were supported by our measurements, showing increased retinal thickness in the central foveal region (Table 2, Fig. 1).

The mean values of total macular volume; foveal thickness; central, inner, and outer retinal thicknesses; and the results of the Kruskal-Wallis $\mathrm{H}$ test for comparison of four groups are shown in Table 2 . The total macular volume and the retinal thickness of the parafoveal region (inner and outer retinal thicknesses) were similar in the four groups (Table 2). The mean values of foveal thickness and central retinal thickness from group I to group III decreased toward the values of group IV. The Kruskal-Wallis H test showed no significant differences between groups I, II, and III (foveal thickness, $P=0.148$; central retinal thickness, $P=0.177$, respectively). For foveal thickness and central retinal thickness, all groups were com- pared by Mann-Whitney test (Table 3). Significant differences were found between the premature and control eyes.

GEE was performed to determine the relation of prematurity and ROP in the development of higher central retinal thickness compared to full-term subjects. At first, the cutoff point was determined by ROC curve analysis (area under the curve [AUC]: $0.865 \pm 0.059$, mean $\pm \mathrm{SD}, P<0.001 ; 95 \% \mathrm{CI}$ : $0.749-0.981)$. The cutoff point of central retinal thickness was $209 \mu \mathrm{m}$ (sensitivity: 0.828; specificity: 0.818). GEE statistical analysis indicated a highly significant effect of ROP stages $(P=$ 0.003 ) and a less than significant effect of category of prematurity, characterized with gestational age at birth $<30$ weeks and birth weight $<1250 \mathrm{~g}(P=0.063)$.

\section{Discussion}

In this novel study, the macular structure of formerly preterm children was investigated by OCT. Three groups were compared to normal age-matched volunteers: group I, eyes with laser treated ROP; group II, eyes with spontaneously regressed mild ROP; and group III, eyes without ROP.

In formerly preterm children with normal posterior pole and with BCVA 1.0, a nearly continuous layer was imaged between the lamina limitans interna and the photoreceptor layer, corresponding to inner retinal layers in the central mac-

TABLE 2. Mean of OCT Parameters

\begin{tabular}{|c|c|c|c|c|c|}
\hline & Group I & Group II & Group III & Group IV & $\boldsymbol{P}$ \\
\hline Total macular volume $\left(\mathrm{mm}^{3}\right)$ & $\begin{array}{c}7.1 \pm 0.3 \\
(6.47-7.55)\end{array}$ & $\begin{array}{c}6.9 \pm 0.4 \\
(6.2-7.52)\end{array}$ & $\begin{array}{l}6.7 \pm 0.33 \\
(6.22-6.99)\end{array}$ & $\begin{array}{c}7.1 \pm 0.3 \\
(6.29-7.39)\end{array}$ & 0.095 \\
\hline Foveal thickness $(\mu \mathrm{m})$ & $\begin{array}{c}220.4 \pm 39.1 \\
(165-284)\end{array}$ & $\begin{array}{c}198.6 \pm 23.6 \\
(176-248)\end{array}$ & $\begin{array}{c}190.7 \pm 28.9 \\
(160-231)\end{array}$ & $\begin{array}{c}164.7 \pm 16.7 \\
(136-191)\end{array}$ & 0.002 \\
\hline Central retinal thickness $(\mu \mathrm{m})$ & $\begin{array}{c}240.6 \pm 28.9 \\
(201-286)\end{array}$ & $\begin{array}{c}223.3 \pm 14.7 \\
(208-253)\end{array}$ & $\begin{array}{r}218.9 \pm 19 \\
(191-248)\end{array}$ & $\begin{array}{c}199.6 \pm 14.5 \\
(171-221)\end{array}$ & 0.002 \\
\hline Inner retinal thickness $(\mu \mathrm{m})$ & $\begin{array}{c}272.7 \pm 23.5 \\
(210-291)\end{array}$ & $\begin{array}{c}269.4 \pm 15.9 \\
(244-295)\end{array}$ & $\begin{array}{c}269.9 \pm 14.7 \\
(249-291)\end{array}$ & $\begin{array}{c}273.1 \pm 13.5 \\
(256-295)\end{array}$ & 0.65 \\
\hline Outer retinal thickness $(\mu \mathrm{m})$ & $\begin{array}{c}243.4 \pm 18.6 \\
(198-267)\end{array}$ & $\begin{array}{c}239.9 \pm 17.8 \\
(210-264)\end{array}$ & $\begin{array}{c}239.7 \pm 18.5 \\
(217-279)\end{array}$ & $\begin{array}{r}249.9 \pm 9.8 \\
(235-262)\end{array}$ & 0.252 \\
\hline
\end{tabular}

Data are expressed as the mean \pm SD (range). Results of Kruskal-Wallis H test, asymptomatic significance level for the four groups. All groups were compared with each other (10 eyes and 10 children/group). Significant differences $(P)$ are italic. 
TABLE 3. Mann-Whitney Test Results

\begin{tabular}{lccc}
\hline & $\begin{array}{c}\text { Group I } \\
\text { vs. IV }\end{array}$ & $\begin{array}{c}\text { Group II } \\
\text { vs. IV }\end{array}$ & $\begin{array}{c}\text { Group III } \\
\text { vs. IV }\end{array}$ \\
\hline Foveal thickness & 0.001 & 0.000 & 0.095 \\
Central retinal thickness & 0.002 & 0.001 & 0.020 \\
\hline
\end{tabular}

Test was performed for comparison of preterm groups (I-III) and control subjects (group IV) in pairs. Exact significances are shown. Each group was compared with group IV.

ular region. The foveal depression became smooth. Foveal and central retinal thicknesses were significantly larger in eyes with ROP (groups I and II) than in normal eyes (group IV). The values of these parameters in eyes of preterm children without ROP (group III) were between those of group IV and of groups I and II. The Mann-Whitney test showed a significant difference in the central retinal thickness of the three preterm groups compared with the control group. At the same time, the foveal thickness was similar in groups III and IV. The parafoveal region (inner and outer retinal thicknesses) in formerly preterm children did not differ significantly from full-term agematched volunteers. The thickened central region in formerly preterm children (groups I, II, and III) did not affect the value of the total macular volume, and it was not significantly higher than in the full-term group.

A limitation of this study is the small sample size, which precluded a definitive conclusion. The subtle modification of the central macular region seemed to be especially related to the development of the retinopathy. At the same time, the role of the premature birth characterized by gestational age $\leq 30$ weeks at birth and birth weight $\leq 1250 \mathrm{~g}$ could also be considered, since the statistical analysis showed near significant results.

One of the key findings of our study is that OCT imaging showed quantitative modifications in the macular structure of formerly preterm children. The changes could reflect mainly the interrupted development of the eye. A smaller than normal foveal avascular zone was observed in a fluorescein angiographic study performed on formerly preterm children. ${ }^{14}$ The foveal avascular zone is originally densely vascularized, and normally this fine meshwork undergoes regression by apoptosis during development. The results of this study suggest that the process does not occur in children born before the 30th gestational week. The small avascular zone did not correlate with visual acuity. ${ }^{14}$ Similarly, in the present study, every eye of formerly preterm children had normal visual acuity (1.0), despite a thicker central retinal region compared with full-term subjects.

Additional evidence could be provided by electroretinographic (ERG) studies. Recent studies reported significant deficits in amplitude and implicit time of multifocal ERG responses among children with a history of ROP. ${ }^{11}$ Because bipolar cells make the main contribution to the multifocal ERG responses, the large discrepancy between the ROP and control amplitudes in the central rings raises the possibility that the difference in bipolar cell density is greatest in the central retina. The authors previously suggested that the developmental redistribution of the central retina is altered in ROP. In normal foveal development, the diameter of the rod-free zone decreases from approximately $1400 \mu \mathrm{m}$ at 26 weeks' gestation to $500 \mu \mathrm{m}$ in the mature eye, as cone outer segments elongate and inner segments become more slender., 9,15 The foveal cone outer segments pack more tightly together, affording improved acuity. ${ }^{15,16}$ The foveal cone nuclei and inner retinal cells move away from the tightly packed foveal cone outer segments. ${ }^{17}$ Thus, as normal development proceeds, the distance from the center of the fovea to the cone photoreceptor nuclei and bipolar cells increases. ${ }^{17}$ The decrease or absence of this migration in preterm infants can be an explanation for the diminution of foveal depression and the continuity of bipolar and amacrine cell layer, seen on OCT scans.

Similar changes are described in myopia. The total macular volume is decreased, whereas the thickness of the fovea is increased. ${ }^{18}$ Retinal thickness correlates with the axial length and refractive errors. ${ }^{19,20}$ It is also known that high spherical equivalent is generally associated with long axial length in myopic eyes, ${ }^{21}$ and low birth weight children at age 10 to 12 years have an increased prevalence of all refractive errors. ${ }^{22}$ To rule out this "stretch effect" due to myopia, we excluded patients from our study who had myopia higher than $-3.0 \mathrm{D}$ spherical equivalent. In our study, we also found no difference between the four groups concerning axial length. It also corresponds to the literature data, which shows that prematurity is associated with refractive and not axial myopia. ${ }^{23,24}$

In summary, in this case-control study with a standardized clinical protocol used to perform OCT measurements, we found that macular structure was slightly different in preadolescents who were formerly preterm, compared with children who had been born at full term. The central retinal region became larger, and the foveal depression was decreased, due to the continuity of the inner retinal layers observed under the foveal pit. Data from OCT images indicate that the mechanism of these changes may be impairment of the normal centrifugal movement of foveal cone nuclei and inner retinal cells during development. To our knowledge, this novel study provides the first estimates of macular volume in formerly preterm children. Large-scale studies are needed to evaluate the clinical importance of a thickened fovea in preterm children.

\section{References}

1. Gallo JE, Lennerstrand G. A population based study of ocular abnormalities in premature children aged 5 to 10 years. Am J Opbthalmol. 1991;111:539-547.

2. Keith CG, Kitchen WH. Ocular morbidity in infants of very low birthweight. Br J Ophthalmol. 1983;67:302-305.

3. Dowdeswell HJ, Slater AM, Broomhall J, Tripp J. Visual deficits in children born at less than 32 weeks' gestation with and without major ocular pathology and cerebral damage. Br J Ophthalmol. 1995;79:447-452.

4. Snir M, Nissenkorn I, Sherf I, Cohen S, Sira IB. Visual acuity, strabismus and amblyopia in preterm babies with and without retinopathy of prematurity. Ann Opbthalmol. 1988;20:256-258.

5. Hungerford J, Stewart A, Hope P. Ocular sequela of preterm birth and their relation to ultrasound evidence of cerebral damage. $\mathrm{BrJ}$ Ophthalmol. 1986;70:463-468.

6. Abramov I, Hainlina L, Lennerise E, Brown A. Changes in visual functions of children exposed as infants to prolonged illumination. J Am Optometric Assoc. 1985;56:614-619.

7. Dobson V, Quinn GE, Abramov I, Hardy KJ, Tung B. Color vision measured with pseudoisochromatic plates at five and a half years in eyes from the Cryo-Rop study. Invest Opbthalmol Vis Sci. 1996;37.2467-2474.

8. Reisner DS, Hansen RM, Findl O, Petersen RA, Fulton AB. Dark adapted thresholds in children with histories of mild retinopathy of prematurity. Invest Ophthalmol Vis Sci. 1997;38(6):1175-1183.

9. Hendrickson AE. Primate foveal development: a microcosm of current questions in neurobiology. Invest Opbthalmol Vis Sci. 1994;35:3129-3133.

10. Provis JM, Sandercoe T, Hendrickson AE. Astrocytes and blood vessels define the foveal rim during primate retinal development. Invest Ophthalmol Vis Sci. 2000;41(10):2827-2836.

11. Fulton AB, Hansen RM, Moskowitz A, Barnaby AM. Multifocal ERG in subjects with a history of retinopathy of prematurity. Doc Ophthalmol. 2005;111:7-13.

12. Lederer DE, Joel S, Hertzmark E, Heltzer J, Mattox C, Fujimoto J. Analysis of macular volume in normal and glaucomatous eyes using 
optical coherence tomography. Am J Ophthalmol. 2003;135:838843.

13. Gürses-Özden R, Teng C, Vessani R, Zafar S, Liebmann JM, Ritch R. Macular and retinal nerve fiber layer thickness measurement reproducibility using optical coherence tomography (OCT3). J Glaucoma. 2004;13(3):238-244.

14. Mintz-Hittner HA, Knight-Nanan DM, Satriano DR, Kretzer FL. A small avascular zone may be an historic mark of prematurity. Ophthalmology. 1999;106:1409-1413.

15. Yuodelis C, Hendrickson A. A qualitative and quantitative analysis of the human fovea during development. Vision Res. 1986;26(6): 847-855.

16. Hendrickson A, Yuodelis C. The morphological development of the human fovea. Ophthalmology. 1984;91:603-612.

17. Springer AD. New role for the primate fovea: a retinal excavation determines photoreceptor deployment and shape. Vis Neurosci. 1999;16(4):629-636.

18. Lim MCC, Hoh ST, Foster PJ, et al. Use of optical coherence tomography to assess variations in macular thickness in myopia. Invest Ophthalmol Vis Sci. 2005;46(3):974-978.
19. Huynh SC, Wang XY, Rochtchina E, Mitchell P. Distribution of macular thickness by optical coherence tomography: findings from population-based study of 6-year-old children. Invest Ophthalmol Vis Sci. 2006;47(6):2351-2357.

20. Luo HD, Gazzard G, Fong A, et al. Myopia, axial length, and OCT characteristics of the macula in Singaporean children. Invest Ophthalmol Vis Sci. 2006;47(7):2773-2781.

21. Barcsay G, Nagy ZZ, Németh J. Distribution of axial corneal and combined ametropia in a refractive surgery unit. Eur J Ophthalmol. 2003; 13:739-744.

22. O'Connor AR, Stephenson TJ, Johnson A, Tobin MIJ, Ratib S, Fielder AR. Change of refractive state and eye size in children of birth weight less than 1701 g. Br J Ophthalmol. 2006;90(4):456460.

23. Fledelius HC. Preterm delivery and subsequent ocular development. A 7-10 year follow-up of children screened 1982-84 for ROP refraction. Acta Ophthalmol Scand. 1996;74:297-300.

24. Gallo JE, Holmström G, Kugelberg U, Hedquist B, Lennerstrand G. Regressed retinopathy of prematurity and its sequela in children aged 5-10 years. Br J Ophthalmol. 1991;75:527-531. 